\title{
WORK-RELATED PSYCHOSOCIAL RISK FACTORS AND CARE WORKERS MENTAL HEALTH (IN ESTONIAN NURSING HOMES)
}

\author{
Jaana SEPP', Marina JÄRVIS ${ }^{2}$, Karin REINHOLD ${ }^{2}$ \\ ${ }^{1}$ Tallinn Health Care College, Tallinn, Estonia \\ ${ }^{2}$ Tallinn University of Technology, Tallinn, Estonia \\ Corresponding author's e-mail: jaana.sepp@ttk.ee
}

\begin{abstract}
The humankind is ageing rapidly, and as a result, there is an increasing need for old people's homes. The nursing homes face different problems in financing and recruiting the labour force and management. Lack of resources causes the situation, when managers have to find possibilities to accomplish services and to provide quality care with the limited funds. This situation has an additional impact on the nursing professionals, who have to deal with many psychosocial risk factors in their work. The aim of the paper is to explore the work-related psychosocial risk factors and their relationships with mental health problems (MHPs) amongst care workers. A cross-sectional survey was undertaken amongst the care workers in nine Estonian nursing homes. Psychosocial work factors and MHPs (stress, somatic symptoms, depressive symptoms, burnout, cognitive symptoms, and sleep disorders) were analysed using the second version of the Copenhagen Psychosocial Questionnaire (COPSOQ II). Descriptive statistics and Pearson's $r$ correlation were used to analyse the data. The analysis was based on 340 care worker surveys. The highest mean scores for the studied work-related psychosocial factors were recorded for the quantitative demands, influence, rewards, role conflicts, trust, insecurity and work-family balance. Low mean scores were recorded for the meaning of work, role clarity, social relationships at work. The lowest score was followed by burnout and the highest - by cognitive symptoms.
\end{abstract}

Keywords: Psychosocial Risk Factors, Mental Health Problems, Stress, Burnout, Nursing.

JEL Classification: J14, J28

\section{INTRODUCTION}

The study of nursing homes in ten nations (Ribbe et al., 1997) was one of the first papers dedicated to analysis of nursing homes for ageing people. Already then (in the 1990-s), flexibility, co-operation with other health and social services, sharing of responsibility for disabled elderly people and innovations in care were required for the nursing home sector in every country, particularly in the context of scarcity of resources and emergence of future population with greater selfawareness of care needs (Steel, Sherwood \& Ribbe, 1997).

Working environment can influence mental and physical health of the care workers. Workplace has a significant impact on the workers' health and well-being 
(Gabriel \& Liimatainen, 2000), effectiveness and productivity of the workers as well as organisations (Leka, Van Wassenhove \& Jain, 2015). There are many occupational risk factors in healthcare organisations, such as nursing homes and hospitals (Sepp et al., 2015). Psychosocial risk factors and work-related stress are still an issue that needs to be addressed and made more understandable (Leka \& Jain, 2010). Health care psychosocial risk factors have special aspects, they are connected with patient safety and quality of care. Previous studies show that those workers, who suffer from cognitive, depressive or emotional symptoms, could not provide safe and quality services to the patients (Hamdan, 2013; German \& Gumming, 2010; Van Beek et al., 2012). Poor psychosocial work environment can cause anxiety, burnout, depression, and sleeping problems. Quantitative and emotional demands, work pace, role conflicts and relationships at work are negatively related with the workers' mental health. Work-family and role conflicts and job insecurity have significant impact on workers' stress (Freimann \& Merisalu, 2015).

Nursing has long been considered one of the most stressful professions (Lambert \& Lambert, 2001). The main stressors include long hours, heavy workload, lack of influence within the workplace, insufficient resources, role ambiguity, experiences of aggression (Lim, Bogossian \& Ahem, 2010), and lack of support and recognition from co-workers and the management (Lewis et al., 2010).

Trustful work environment, clear work organisation, open communication, involvement in decision-making process increase workers' commitment, motivation and satisfaction and decrease mental health problems (Olsen, 2012). Rewards and quality of leadership are also strongly related with the workers' wellbeing, motivation and mental health (Sepp \& Tint, 2017; Toode et al., 2015). Previous studies show that stress, burnout, somatic and cognitive stress symptoms are related to the physical and emotional overwork (Freimann et al., 2013; 2016). Long workdays and shift work-caused problem with family, stress, emotional demands like those that work pressure, and the role conflicts, unclear tasks correlate with sleep disorders and exhaustion (Freimann et al., 2016). Previous studies also show that distress, somatic symptoms, emotional overwork and depersonalisation are connected with musculoskeletal disorders and are associated with pain (Freimann \& Merisalu, 2015; Freimann et al., 2013; 2016).

To provide patient safety and quality of care, organisations need to keep their attention on supportive work environment and workers' motivation which are closely related with work organisation, workload, workers' satisfaction, cooperation and collaboration between colleagues and supervisors, as well as opportunities to learn from mistakes without fear to be punished (Sepp \& Tint, 2017; Toode et al., 2015).

One important finding of the Norwegian study (Begat, Ellefsen, \& Severinsson, 2005) on nurses was that there is a significant correlation between the factor "independence" and "relations with colleagues", as well as between "collaboration and good communication" and "work demands" $(p<0.05)$. When nurses realize that they are able to communicate and collaborate, they feel that they find it easier to deal with morally sensitive situations. This, in turn, helps the nurse to provide 
qualitative care. "Job stress and anxiety" and "work demands" are found to have a mild correlation with "ethical conflicts".

Apart from complex physical requirements, up to $40 \%$ of staff time is spent managing challenging behaviour (Kleimann et al., 2004). This contributes to staff stress, strain (Edberg et al., 2008) and potentially to staff turnover.

The authors also found job satisfaction to be higher among staff who had received more training in assessment or who practiced person-centred care (Zimmermann et al., 2005). A systematic study conducted in the Netherlands (Van den Pol-Grevelink, Jukema \& Smits, 2011) showed that person-centred care generally increased job satisfaction and personal accomplishment, and reduced job demands and emotional exhaustion, reduced sickness absence and stress.

The European Commission provides guidance that needs to be integrated in the working practices in the workplace, recommending on the management methods to be applied to reduce the work-related stress of employees. The first step is to identify the risk, its sources and consequences by monitoring the content, conditions, relationships, health, well-being and performance (Giurgiu et al. 2015). It has been found that the psychosocial situation of employees is linked to the company's economic indicators, first of all regarding the increasing costs caused by accidents at work (Aiken \& Patrician, 2000; Duncan, Rodney \& Thorne, 2014). The effectiveness of risk management lies in its impact and scope. As a result of proactive safety management, the use of financial resources reduces the amount of compensation for accidents at work, incapacity for work, and it is directly related to the company's economic performance and management effectiveness (Järvis \& Tint, 2009). In healthcare companies, effective management of psychosocial risks is linked to employee satisfaction, motivation, healthy and productive work environments (McHugh et al., 2011; Titzer, Shirey \& Hauck, 2014). In the previous study, a link between patient safety and psychosocial risk factors was established. Due to stress, 110 nurses made a total of 205 medication-related errors in 12 months, making 1 to 7 mistakes per nurse. In order to ensure patient safety, it is important to know the negative impact of psychosocial risk factors on the mental health of nurses and trainees in order to improve the quality of nursing activities (Zaree et al. 2017). Technological developments have led to increased demands towards the physical and mental abilities of workers. Many jobs have changed their profile and character (Freimann \& Merisalu, 2015). The labour market is struggling for the best workers and talents. Employers are forced to implement modern working methods to ensure stability and survival of highly qualified workers in organizations. Departure of a staff leads to the costs that can be minimized or prevented by effective personnel management (Aiken \& Patrician, 2000). In order to maintain mental health of the employees, proactive safety management needs to be provided by applying effective strategies.

Based on the previous research in the area of psychosocial risk factors of care workers in the nursing homes addressed above, the aim of the present study is to explore the relationship between high work demands, the relationships among coworkers, negative work interfaces, work organization and management, and their influence on the worker's mental health. 
Four hypotheses were put forward:

H1 Work demands positively correlate with mental health problems.

$\mathrm{H} 2$ Positive relationships negatively correlate with mental health problems.

H3 Individual negative work interfaces such as job insecurity and low job satisfaction positively correlate with mental health problems.

H4 Adequate work organization and job content negatively correlate with mental health problems.

\section{METHODS}

\subsection{Study design and sample}

In 2017, a cross-sectional survey was conducted among care workers at nine selected Estonian nursing homes. We used a paper-based questionnaire, which was sent to all employed full-time 509 care workers at the selected organizations. The participation in the survey was voluntary which was also stated in the cover letter of the study. Permission for the survey was obtained from the top manager of each organization.

Demographic data of the sample are presented in Table 1. The data demonstrate that among 340 respondents (66.79\% of the sample), 332 (97.6\%) were females. The distribution of respondents according to their age group shows that 111 respondents $(32.6 \%)$ are in the age group 45-54, followed by 70 respondents $(20.6 \%)$ in the age group 55-65 years, and 69 respondents $(20.3 \%)$ in the age group 35-44 years old. There were 14 respondents (41\%), whose age was over 65 years, and 44 respondents $(12.9 \%$ ), who were younger than 24 years of age. $9.4 \%$ (32) of respondents were in the age group of 25-34. $13.8 \%$ of the respondents had 1 year of work experience, $45.9 \%-1-5$ years, $22.4 \%-6-10$ years, and $17.9 \%$ of the respondents had more than 10 years of experience.

Table 1. Demographics/background information for study participants $(n=340)$

\begin{tabular}{|l|r|r|r|}
\hline \multicolumn{1}{|c|}{ Demographic variables } & \multicolumn{1}{|c|}{ Category } & \multicolumn{1}{c|}{ Frequency } & \multicolumn{1}{c|}{ Proportion } \\
\hline Gender & Male & 5 & $2 \%$ \\
\hline & Female & 332 & $98 \%$ \\
\hline Age & $<24$ & 44 & $13 \%$ \\
\hline & $25-34$ & 32 & $9 \%$ \\
\hline & $35-44$ & 69 & $20 \%$ \\
\hline & $45-54$ & 111 & $33 \%$ \\
\hline & $55-65$ & 70 & $21 \%$ \\
\hline Length of employment (y) & $>65$ & 14 & $4 \%$ \\
\hline & $<1$ year & 47 & $14 \%$ \\
\hline & $1-5$ years & 156 & $46 \%$ \\
\hline Working time & $6-10$ years & 76 & $22 \%$ \\
\hline & Over 10 years & 13 & $18 \%$ \\
\hline & Full time & 327 & $95 \%$ \\
\hline & More than full time 1.0 & 16 & $5 \%$ \\
\hline
\end{tabular}




\subsection{Questionnaire}

The Copenhagen Psychosocial Questionnaire, the second version (COPSOQII), was used to measure work-related psychosocial factors and mental health problems (MHPs) (Kristensen et al., 2005). A licensed translator performed translation and back translation of the questionnaire (into Estonian and Russian). Cronbach's alphas were calculated to assess the internal consistency of the scales for psychosocial factors and MHPs. In our study, psychosocial factors were assessed using 115 items that covered the following four psychosocial domains:

- demands at work;

- work organisation and job content;

- interpersonal relationships and leadership;

- values at the workplace.

To assess MHPs, we used 24 items grouped into the following six scales:

Stress, somatic stress symptoms, depressive symptoms, burnout, cognitive symptoms, and sleep disorders. Most of the scales of psychosocial factors and MHPs included three or four items, but two scales - predictability and work versatility - included only two items. The majority of items were scored according to 6 point Likert scale (excl. questions 18, 20, 21, 22, 23, 24, 25, 26, 30, 31, 35, 36, $37,38,39,40,41,42,43,44$, which were assessed according to 5-point scale, and questions 32, 33 and 34, which were assessed according to 4-point scale). The authors also removed the scale - work versatility. In the Estonian version of the questionnaire, the scale was excluded because of low Cronbach's alpha (0.140), item internal correlation was extremely low $(r=0.076)$.

\subsection{Statistical analysis}

Raw data were compared using T-test and appropriate probabilities were adjusted for the number of simultaneous tests, using the sequential Bonferroni correction. The analyses were carried out using SPSS Statistics 24.0.

Table $2 a$ presents the original and Table $2 b$ - the final mean score, standard deviation and Cronbach's alphas for self-reported psychosocial factors and mental health problems. In Table $2 \mathrm{a}$, the scales marked have been modified (question removed) in order to reach higher Cronbach's alpha. Table $2 b$ is the final table. Thanks to data processing, statistically significant reliability coefficient of the factors can be seen.

Overview of items, modified during detailed analysis, quantitative demands. Cronbach's alpha for the initial set of questions included into the factor (question 12:1-4) was 0.658. We are looking for the score $\alpha>0.7$ for high internal consistency. In this case, $\alpha=0.658$ which shows that the questionnaire is not as reliable as we expected. Items statistics for each item of the question show that question 12-4 (Do you have enough time for your tasks?) does not tap well into the same content.

Work pace. Cronbach's alpha for the initial set of questions included into the factor was 0.849. The items have similar scores. Each item correlates with the overall questionnaire score. After deleting any of the items from the set, Cronbach's 
alpha score will not increase. None of the question items included into set would be deleted.

Possibility for development. Cronbach's alpha for the initial set of questions included into the factor (question 18:1-4) was 0.761 . The items statistics for each item of the question show that it is not clear for the question 18-1 (Does your work require initiative?), whether it taps well into the content or not. Items correlation statistics show that question 18-1 does not correlate well with all other items. Question 18-1 may be problematic, as it has relatively weak correlation with questions 18-2 and $18.3(r<0.3)$. According to the statistical information, there was no need to remove item 18-1 from the factor "Work organization and job content". The procedure "Corrected Item - Total Correlation" is more than $r=0.3$ and besides that score goes down if we deleted item 18-1.

Commitment to the workplace. The initial scale included four items: questions 21:1-4. Cronbach's alpha was 0.455 . Detailed analyses of all items included into the scale showed that question 21-4 does not suit well with the rest of the items from this scale: the average response is higher than for the other items, correlations with the other items of the scale do not exist (all are lower than 0.3). After excluding item 21-4 from the scale, the Cronbach's alpha score of the scale went up: the new score was 0.575 . This result is better, but also not good enough.

Social inclusiveness. Cronbach's alpha score for "Social Inclusiveness Scale", where all four questions were included, was 0.609. After detailed analysis of the items included into the scale, item 37-4 was eliminated. Cronbach's alpha score increased after this activity and the new score was 0.670 .

\section{RESULTS}

Table $2 \mathrm{~b}$ presents the mean scores, standard deviations and Cronbach's alphas for self-reported psychosocial factors and Mental Health Problems (MHP). The psychosocial factors with the highest mean scores were quantitative demands, influence, rewards, role conflicts, trust, insecurity, and work-family balance. Low mean scores were recorded for the meaning of the work, role clarity, social relationships at work. The mean scores for six MHP's ranged from 14.16 to 16.74; the lowest score was for burnout and the highest - for cognitive symptoms. The high mean score was also recorded for the somatic symptoms (16.71).

Table 2. Number of item means, standard deviation and Cronbach's alphas for work-related psychosocial factors and mental health problems (340 respondents)

\begin{tabular}{|c|c|c|c|c|c|c|c|c|}
\hline \multicolumn{5}{|c|}{ Table 2a } & \multicolumn{4}{|c|}{ Table 2b Final score } \\
\hline $\begin{array}{l}\text { Psychosocial } \\
\text { factors and } \\
\text { MHPs (scale) }\end{array}$ & $\begin{array}{l}\text { Num- } \\
\text { ber of } \\
\text { items }\end{array}$ & Mean & SD & $\begin{array}{l}\text { Cronbach's } \\
\text { alpha }\end{array}$ & $\begin{array}{l}\text { Num- } \\
\text { ber of } \\
\text { items }\end{array}$ & Mean & SD & $\begin{array}{c}\text { Cronbach's } \\
\text { alpha }\end{array}$ \\
\hline \multicolumn{9}{|c|}{ Demands at work } \\
\hline $\begin{array}{l}\text { Quantitative } \\
\text { demands* }\end{array}$ & 4 & 12.78 & 3.899 & 0.658 & 3 & 10.6 & 3.869 & 0.858 \\
\hline Work pace & 3 & 7.52 & 2.857 & 0.849 & 3 & 7.52 & 2.857 & 0.849 \\
\hline $\begin{array}{l}\text { Cognitive } \\
\text { demands }\end{array}$ & 4 & 9.82 & 2.703 & 0.676 & 4 & 9.82 & 2.703 & 0.676 \\
\hline
\end{tabular}




\begin{tabular}{|c|c|c|c|c|c|c|c|c|}
\hline $\begin{array}{l}\text { Emotional } \\
\text { demands }\end{array}$ & 4 & 9.42 & 3.002 & 0.712 & 4 & 9.42 & 3.002 & 0.712 \\
\hline $\begin{array}{l}\text { Demands for } \\
\text { hiding emotions }\end{array}$ & 3 & 6.96 & 2.744 & 0.739 & 3 & 6.96 & 2.744 & 0.739 \\
\hline \multicolumn{9}{|c|}{ Work organization and job content } \\
\hline Influence & 4 & 14.06 & 3.998 & 0.777 & 4 & 14.06 & 3.998 & 0.777 \\
\hline $\begin{array}{l}\text { Possibility for } \\
\text { development }\end{array}$ & 4 & 8.73 & 2.555 & 0.761 & 4 & 8.73 & 2.555 & 0.761 \\
\hline $\begin{array}{l}\text { Work } \\
\text { versatility* }\end{array}$ & 2 & 4.12 & 1.439 & 0.14 & \multicolumn{4}{|c|}{ Removed } \\
\hline $\begin{array}{l}\text { Meaning of } \\
\text { work }\end{array}$ & 3 & 5.57 & 2.153 & 0.836 & 3 & 5.57 & 2.153 & 0.836 \\
\hline $\begin{array}{l}\text { Commitment to } \\
\text { the workplace* }\end{array}$ & 4 & 11.05 & 2.705 & 0.455 & 3 & 7.57 & 2.257 & 0.575 \\
\hline \multicolumn{9}{|c|}{ Interpersonal relationships and leadership } \\
\hline Predictability & 2 & 4.66 & 1.58 & 0.725 & 2 & 4.66 & 1.58 & 0.725 \\
\hline Rewards & 5 & 12.05 & 3.894 & 0.853 & 5 & 12.05 & 3.894 & 0.853 \\
\hline Role clarity & 3 & 5.28 & 1.806 & 0.848 & 3 & 5.28 & 1.806 & 0.848 \\
\hline Role conflicts & 4 & 12.35 & 3.632 & 0.835 & 4 & 12.35 & 3.632 & 0.835 \\
\hline $\begin{array}{l}\text { Quality of } \\
\text { leadership }\end{array}$ & 4 & 9.61 & 2.996 & 0.848 & 4 & 9.61 & 2.996 & 0.848 \\
\hline $\begin{array}{l}\text { Social support } \\
\text { from colleagues }\end{array}$ & 3 & 6.82 & 2.527 & 0.763 & 3 & 6.82 & 2.527 & 0.763 \\
\hline $\begin{array}{l}\text { Social support } \\
\text { from supervisor }\end{array}$ & 3 & 7.46 & 2.936 & 0.827 & 3 & 7.46 & 2.936 & 0.827 \\
\hline $\begin{array}{l}\text { Social } \\
\text { relationships at } \\
\text { work }\end{array}$ & 3 & 5.85 & 2.037 & 0.774 & 3 & 5.85 & 2.037 & 0.774 \\
\hline \multicolumn{9}{|l|}{$\begin{array}{l}\text { Values at the } \\
\text { workplace }\end{array}$} \\
\hline Trust & 7 & 20.23 & 4.198 & 0.622 & 7 & 20.23 & 4.198 & 0.622 \\
\hline $\begin{array}{l}\text { Justice and } \\
\text { respect }\end{array}$ & 4 & 9.97 & 2.921 & 0.853 & 4 & 9.97 & 2.921 & 0.853 \\
\hline $\begin{array}{l}\text { Social } \\
\text { inclusiveness* }\end{array}$ & 4 & 10.7 & 3.175 & 0.609 & 3 & 7.79 & 2.732 & 0.67 \\
\hline \multicolumn{9}{|c|}{ Adequate work organization } \\
\hline Insecurity & 4 & 16.06 & 3.587 & 0.839 & 4 & 16.06 & 3.587 & 0.839 \\
\hline $\begin{array}{l}\text { Satisfaction } \\
\text { with work }\end{array}$ & 4 & 7.98 & 2.256 & 0.823 & 4 & 7.98 & 2.256 & 0.823 \\
\hline $\begin{array}{l}\text { Work-family } \\
\text { balance }\end{array}$ & 4 & 11.58 & 2.989 & 0.827 & 4 & 11.58 & 2.989 & 0.827 \\
\hline $\begin{array}{l}\text { Conflicts } \\
\text { between family } \\
\text { and work }\end{array}$ & 2 & 6.86 & 1.321 & 0.852 & 2 & 6.86 & 1.321 & 0.852 \\
\hline \multicolumn{9}{|c|}{ Mental health problems } \\
\hline Stress & 4 & 15.06 & 2.843 & 0.845 & 4 & 15.06 & 2.843 & 0.845 \\
\hline $\begin{array}{l}\text { Somatic } \\
\text { symptoms }\end{array}$ & 4 & 16.71 & 2.284 & 0.641 & 4 & 16.71 & 2.284 & 0.641 \\
\hline $\begin{array}{l}\text { Depressive } \\
\text { symptoms }\end{array}$ & 4 & 16.34 & 2.452 & 0.736 & 4 & 16.34 & 2.452 & 0.736 \\
\hline Burnout & 4 & 14.16 & 3.436 & 0.904 & 4 & 14.16 & 3.436 & 0.904 \\
\hline $\begin{array}{l}\text { Cognitive } \\
\text { symptoms }\end{array}$ & 4 & 16.74 & 2.501 & 0.809 & 4 & 16.74 & 2.501 & 0.809 \\
\hline Sleep disorders & 4 & 15.68 & 3.606 & 0.891 & 4 & 15.68 & 3.606 & 0.891 \\
\hline
\end{tabular}

The majority of scales showed satisfactory Cronbach's alphas, which ranged from 0.904 to 0.712 for the scales of the psychosocial work characteristics and MHPs. The following scales had coefficients of less than 0.700: cognitive demands (0.676); commitment to the workplace (0.575); trust (0.622); social inclusiveness (0.670), and somatic symptoms (0.641). 
The results of analysis of cross-sectional correlations between psychosocial factors (24) and six MHPs are presented in Table 3. Our study results show that the majority of 24 psychosocial factors statistically significantly correlated with burnout, cognitive symptoms and sleep disorders. One psychosocial risk factor, work and family balance, showed positive correlation with all MHPs, while such factors as rewards and quality of leadership showed negative correlations with all MHPs.

Table 3. Pearson's $\boldsymbol{r}$ correlation for psychosocial factors and mental health problems of a group of 340 respondents

\begin{tabular}{|c|c|c|c|c|c|c|}
\hline & $\begin{array}{c}\text { Sleep } \\
\text { disorders }\end{array}$ & Burnout & Stress & $\begin{array}{l}\text { Depressive } \\
\text { symptoms }\end{array}$ & $\begin{array}{c}\text { Somatic } \\
\text { symptoms }\end{array}$ & $\begin{array}{c}\text { Cognitive } \\
\text { symptoms }\end{array}$ \\
\hline \multicolumn{7}{|c|}{ Demands at work } \\
\hline $\begin{array}{l}\text { Quantitative } \\
\text { demands }\end{array}$ & $-0.245^{* *}$ & $-0.229 * *$ & 0.055 & 0.015 & -0.01 & $0.159 * *$ \\
\hline Work pace & -0.083 & -0.005 & 0.071 & -0.012 & 0.016 & 0.025 \\
\hline $\begin{array}{l}\text { Cognitive } \\
\text { demands }\end{array}$ & $0.150 * *$ & $0.108^{*}$ & 0.082 & 0.093 & 0.083 & -0.007 \\
\hline $\begin{array}{l}\text { Emotional } \\
\text { demands }\end{array}$ & $0.171 * *$ & $0.201 * *$ & $0.169 * *$ & $0.174 * *$ & $0.226 * *$ & 0.063 \\
\hline $\begin{array}{l}\text { Demands for } \\
\text { hiding emotions }\end{array}$ & $0.254 * *$ & $0.190 * *$ & 0.051 & $0.118^{*}$ & $0.124 *$ & -0.011 \\
\hline \multicolumn{7}{|c|}{ Work organisation and job content } \\
\hline Influence & -0.023 & $-0.141 * *$ & $-0.281 * *$ & $-0.118 *$ & 0.002 & $-0.217 * *$ \\
\hline $\begin{array}{l}\text { Possibility for } \\
\text { development }\end{array}$ & -0.027 & $0.124 *$ & $0.139 *$ & -0.023 & 0.033 & 0.031 \\
\hline $\begin{array}{l}\text { Meaning of } \\
\text { work }\end{array}$ & 0.044 & -0.043 & -0.096 & -0.052 & -0.004 & $-0.171 * *$ \\
\hline $\begin{array}{l}\text { Commitment to } \\
\text { the workplace }\end{array}$ & $-0.242 * *$ & $-0.287 * *$ & $-0.165 * *$ & $-0.161 * *$ & -0.098 & $-0.119^{*}$ \\
\hline \multicolumn{7}{|c|}{ Interpersonal relationships and leadership } \\
\hline Predictability & -0.024 & $-0.150 * *$ & $-0.131 *$ & -0.046 & -0.024 & $-0.193 * *$ \\
\hline Rewards & $-0.330 * *$ & $-0.427 * *$ & $-0.186 * *$ & $-0.227 * *$ & $-0.155^{* *}$ & $-0.178 * *$ \\
\hline Role clarity & $0.166^{* *}$ & 0.102 & -0.093 & -0.049 & 0.021 & $-0.153 * *$ \\
\hline Role conflicts & $-0.166^{* *}$ & $-0.183 * *$ & -0.077 & -0.067 & -0.016 & 0.068 \\
\hline $\begin{array}{l}\text { Quality of } \\
\text { leadership }\end{array}$ & $-0.158 * *$ & $-0.247 * *$ & $-0.217 * *$ & $-0.183 * *$ & $-0.178 * *$ & $-0.321 * *$ \\
\hline $\begin{array}{l}\text { Social support } \\
\text { colleagues }\end{array}$ & $-0.119 *$ & -0.08 & -0.105 & $-0.168 * *$ & -0.035 & $-0.140 * *$ \\
\hline $\begin{array}{l}\text { Social support } \\
\text { management }\end{array}$ & -0.039 & $-0.183 * *$ & $-0.174 * *$ & $-0.114 *$ & -0.098 & $-0.301 * *$ \\
\hline $\begin{array}{l}\text { Social } \\
\text { relationship at } \\
\text { work }\end{array}$ & 0.082 & $0.130 *$ & -0.055 & $-0.136^{*}$ & 0.026 & $-0.126^{*}$ \\
\hline \multicolumn{7}{|c|}{ Adequate work organisation } \\
\hline Insecurity & 0.012 & 0.083 & -0.01 & 0.057 & 0.076 & -0.05 \\
\hline $\begin{array}{l}\text { Satisfaction with } \\
\text { work }\end{array}$ & $-0.203 * *$ & $-0.310^{* *}$ & $-0.184 * *$ & $-0.164 * *$ & -0.106 & $-0.120 *$ \\
\hline $\begin{array}{l}\text { Work-family } \\
\text { balance }\end{array}$ & $0.378 * *$ & $0.523 * *$ & $0.365 * *$ & $0.406 * *$ & $0.294 * *$ & $0.275 * *$ \\
\hline
\end{tabular}




\begin{tabular}{|l|r|r|r|r|r|r|}
\hline $\begin{array}{l}\text { Conflict between } \\
\text { family and work }\end{array}$ & 0.011 & 0.05 & 0.098 & 0.061 & 0.068 & $.188^{* *}$ \\
\hline \multicolumn{7}{|l|}{ Values at the workplace } \\
\hline Trust & -0.028 & 0.009 & 0.001 & 0.01 & -0.055 & -0.019 \\
\hline $\begin{array}{l}\text { Justice and } \\
\text { respect }\end{array}$ & -0.087 & -0.095 & -0.099 & -0.036 & -0.039 & $-0.171^{* *}$ \\
\hline $\begin{array}{l}\text { Social } \\
\text { inclusiveness }\end{array}$ & $-0.112 *$ & $-0.178^{* *}$ & -0.072 & 0.005 & $-0.168 * *$ & -0.046 \\
\hline
\end{tabular}

**Statistically significant $\mathrm{p}$-values $(p<0.01)$

*Statistically significant $\mathrm{p}$-values $(p<0.05)$

All correlations between components are described in detail below.

\subsection{Demands at work}

Quantitative demands negatively correlate with sleep disorders $(r=-0.245$; $p<0.01)$ and burnout $(r=-0.229 ; p<0.01)$; but there is positive correlation with cognitive symptoms $(r=0.159 ; p<0.01)$. Work pace does not have any statistically significant correlations with any MHP. Cognitive demands positively correlate with sleep disorders $(r=0.150 ; p<0.01)$ and burnout $(r=0.108 ; p<0.05)$ (while quantitative demands negatively correlate with these MHPs). Emotional demands factor has positive correlations with almost all MHPs, except cognitive symptoms. Demands for hiding emotions have positive correlations with sleep disorders $(r=0.254 ; p<0.01)$, burnout $(r=0.190 ; p<0.01)$ and somatic symptoms $(r=0.124$; $p<0.05)$.

Quantitative demands is the only psychosocial risk factor, which statistically significantly correlates with cognitive symptoms $(r=0.159 ; p<0.01)$; emotional demands factor is the only one, which correlates with stress $(r=0.169 ; p<0.01)$. Correlation between factors "Emotional demands" and "Stress" shows that the more respondents feel that they have to hide their emotions, the higher stress level they have.

\subsection{Work organization and job content}

Psychosocial risk factor "Influence" has negative correlations with burnout $(r=0.141 ; p<0.01)$, stress $(r=-0.281 ; p<0.01)$, depressive symptoms $(r=-0.118$; $\mathrm{p}<0.05)$ and cognitive symptoms $(r=-0.217 ; p<0.01)$. Factor "Meaning of work" negatively correlates with cognitive symptoms $(r=-0.171 ; p<0.01)$. Commitment to the workplace correlates with almost all MHPs, except somatic symptoms. The "Possibility for development" component is the only one from "Work organizations and job content" section, which has positive correlations with such MHPs as burnout $(r=0.124 ; p<0.05)$ and stress $(r=0.139 ; p<0.05)$.

\subsection{Interpersonal relationships and leadership}

Psychosocial risk factor "Role conflicts" is the only factor, which does not have statistically significant correlation with cognitive symptoms MHP. Predictability correlates negatively with burnout $(r=-0.150 ; p<0.01)$, stress $(r=-0.131 ; p<0.01)$, and cognitive symptoms $(r=-0.193 ; p<0.01)$. "Rewards and quality of leadership" 
factors have negative correlations with all MHPs. "Role clarity" correlates positively with sleep disorders $(r=0.166 ; p<0.01)$, while there is a negative correlation with cognitive symptoms $(r=-0.153 ; p<0.01)$. "Role conflicts" correlate negatively with sleep disorders $(r=-0.166 ; p<0.01)$ and burnout $(r=-0.183 ; p<0.01)$. "Social support from colleagues" correlates negatively with sleep disorders $(r=-0.119 ; p<0.05)$, depressive symptoms $(r=-0.168 ; p<0.01)$, and cognitive symptoms $(r=-0.140 ; p<0.01)$. Comparing to the above described factor, "Social support from management" correlated negatively with depressive symptoms $(r=-0.114 ; p<0.05)$ and cognitive symptoms $(r=-0.301 ; p<0.01)$ (the same like social support from colleagues) and there are correlations with burnout and stress. In addition, "Social relationships at work" correlate negatively with depressive symptoms $(r=-0.136 ; p<0.05)$ and cognitive symptoms $(r=-0.126$; $p<0.05)$, there is also negative correlation between burnout $(r=0.130 ; p<0.05)$.

\subsection{Adequate work organization}

Psychosocial risk factor "Insecurity" does not have any statistically significant correlations with MHPs. "Conflict between family and work" has statistically significant positive correlation only with one MHP - cognitive symptoms $(r=0.188 ; p<0.01)$. "Work - family balance" correlated positively with all MHPs (sleep disorders $(r=0.378 ; p<0.01)$, burnout $(r=0.523 ; p<0.01)$, stress $(r=0.365$; $p<0.01)$, depressive symptoms $(r=0.406 ; p<0.01)$, somatic symptoms $(r=0.294$; $p<0.01)$ and cognitive symptoms $(r=0.275 ; p<0.01))$. "Satisfaction with work" correlates negatively with almost all MHPs except somatic symptoms (sleep disorders $(r=-0.203 ; p<0.01)$, burnout $(r=-0.310 ; p<0.01)$, stress $(r=-0.184$; $p<0.01)$, depressive symptoms $(r=-0.164 ; p<0.01)$, and cognitive symptoms $(r=-0.120 ; p<0.05)$.

\subsection{Symptoms at the workplace}

"Justice and respect" negatively correlates to cognitive symptoms ( $r=-0.171$; $p<0.01$ ), while "Social inclusiveness" correlated negatively with sleep disorders $(r=-0.112 ; p<0.05)$, burnout $(r=-0.178 ; p<0.01)$, and somatic symptoms $(r=-0.168 ; p<0.01)$. Psychosocial risk factor "Trust" has no statistically significant correlations with MHPs.

\subsection{Analysis of psychosocial risk factors}

The correlation between psychosocial risk factors was established. There is significant enough positive correlation (Pearson's $r$ coefficient $>=0.45$ ) between the following factors: quality of leadership and rewards $(r=0.464)$; social support from management and quality of leadership $(r=0.619)$; satisfaction with work and rewards $(r=0.449)$; work - family balance and rewards $(r=0.460)$; justice and respect and quality of leadership $(r=0.464)$; social relationship at work and social support from colleagues $(r=0.504)$; justice and respect and social support from management $(r=0.534)$; and justice and respect and social relationship at work $(r=0.469)$. 


\subsection{Analysis of mental health problems}

The information about the correlation between MHP factors is presented in Table 4. There is significant positive correlation (Pearson's $r$ coefficient $>=0.6$ ) between the following factors: sleep disorders and burnout $(r=0.629)$; stress and burnout $(r=0.673)$; depressive symptoms and stress $(r=0.683)$. Respondents, who experience burnout (the higher is the level), also face sleep disorders more often. Similarly, the higher is the level of stress for the respondents, the more likely he/she develops depressive symptoms and/or burnout syndrome.

Table 4. Correlation between MHP factors

\begin{tabular}{|l|r|r|r|r|c|}
\hline & $\begin{array}{c}\text { Sleep } \\
\text { disorders }\end{array}$ & Burnout & Stress & $\begin{array}{c}\text { Depressive } \\
\text { symptoms }\end{array}$ & $\begin{array}{c}\text { Somatic } \\
\text { symptoms }\end{array}$ \\
\hline Sleep disorders & & & & & \\
\hline Burnout & $0.629^{* *}$ & & & & \\
\hline Stress & $0.478^{* *}$ & $0.673^{* *}$ & & & \\
\hline $\begin{array}{l}\text { Depressive } \\
\text { symptoms }\end{array}$ & $0.507^{* *}$ & $0.582^{* *}$ & $0.683^{* *}$ & & \\
\hline $\begin{array}{l}\text { Somatic } \\
\text { symptoms }\end{array}$ & $0.515^{* *}$ & $0.530^{* *}$ & $0.540^{* *}$ & $0.543^{* *}$ & \\
\hline $\begin{array}{l}\text { Cognitive } \\
\text { symptoms }\end{array}$ & $0.290^{* *}$ & $0.484^{* *}$ & $0.528^{* *}$ & $0.546^{* *}$ & $0.482^{* *}$ \\
\hline
\end{tabular}

\section{DISCUSSION}

The current study has analysed work-related psychosocial risk factors pertaining to care workers in nursing homes. Our study results show that psychosocial risk factors significantly influence the mental health of care workers. We established a strong correlation between the psychosocial risk factors and burnout, stress, sleep disorders, cognitive, depressive and somatic symptoms. Our study also shows that the most common problem for care workers is work organization and job content. Our study results are quite similar to previous study conducted in the Estonian university hospital; researchers also found that work organization influences mental health of the nurses (Freimann \& Merisalu, 2015). Studies show that nurses and care workers do not have opportunities to control work organization including division of labour and work schedule. Workers also do not receive enough support from colleagues and supervisors. Quality of management has a crucial role in nursing because it is strongly related to the workers satisfaction and well-being (Malloy \& Penprase, 2010). Our study shows that quantitative demands are the only psychosocial risk factor, which statistically significantly correlates with cognitive symptoms, and emotional demands correlate to stress. Our results show that inconsistent work organisation can cause memory and concentration problems among the workers and increase burnout and stress (Javaid et al., 2018). 


\subsection{Interpersonal relationships and leadership}

The study has revealed that good relationships at work are very important for workers' mental health. Our results show that respondents who receive sufficient social support from colleagues estimate social relationships at work higher, than those who do not have enough support from colleagues. Good relationships with supervisors influence workers' well-being and decrease the level of stress, depressive and cognitive symptoms and burnout. Psychosocial risk factor, such as work and family balance, showed positive correlation with all MHPs, while factors such as rewards and quality of leadership showed negative correlation with all MHPs. The conflict between family and work has statistically significant positive correlation only with cognitive symptoms. Satisfaction with work correlates negatively with almost all MHPs except somatic symptoms. Justice and respect negatively correlate with cognitive symptoms, while social inclusiveness correlates negatively with sleep disorder, burnout, and somatic symptoms.

\subsection{Hypothesis}

Results of our study reveal that two out of four hypotheses ( $\mathrm{H} 2$ and $\mathrm{H} 4)$ were supported and the remaining two partly supported ( $\mathrm{H} 1$ and $\mathrm{H} 3)$; the results are presented in Table 5.

Table 5. Hypotheses

\begin{tabular}{|c|c|c|c|c|c|c|}
\hline & MHPI & MHPII & MHPIII & MHPIV & MHPV & MHPVI \\
\hline $\begin{array}{l}\text { HI-I Quantitative } \\
\text { demands }\end{array}$ & & & & & & $0.159 * *$ \\
\hline $\begin{array}{l}\text { HI-II Cognitive } \\
\text { demands }\end{array}$ & $0.150 * *$ & $0.108^{*}$ & & & & \\
\hline $\begin{array}{l}\text { HI-III Emotional } \\
\text { demands }\end{array}$ & $0.171 * *$ & $0.201 * *$ & $0.169 * *$ & & $0.226 * *$ & \\
\hline $\begin{array}{l}\text { HII-I Social } \\
\text { relationships at work }\end{array}$ & & & & $-0.136^{*}$ & & $-0.126^{*}$ \\
\hline $\begin{array}{l}\text { HII-II Social support } \\
\text { from colleagues }\end{array}$ & $-0.119 *$ & & & $-0.168 * *$ & & $-0.140 * *$ \\
\hline $\begin{array}{l}\text { HII-III Social support } \\
\text { from management }\end{array}$ & & $-0.183 * *$ & $-0.174 * *$ & $-0.114^{*}$ & & $-0.301 * *$ \\
\hline $\begin{array}{l}\text { HII-IV Quality of } \\
\text { leadership }\end{array}$ & $-0.158 * *$ & $-0.247 * *$ & $-0.217 * *$ & $-0.183 * *$ & $-0.178 * *$ & $-0.321 * *$ \\
\hline HII-V Influence & & $-0.141 * *$ & $-0.281 * *$ & $-0.118 *$ & & $-0.217 * *$ \\
\hline $\begin{array}{l}\text { HIII-I Satisfaction } \\
\text { with work }\end{array}$ & $-0.203 * *$ & $-0.310 * *$ & $-0.184 * *$ & $-0.164 * *$ & & $-0.120^{*}$ \\
\hline $\begin{array}{l}\text { HIV-I Meaning of } \\
\text { work }\end{array}$ & & & & & & $-.171 * *$ \\
\hline $\begin{array}{l}\text { HIV-II Commitment } \\
\text { to the workplace }\end{array}$ & $-0.242 * *$ & $-0.287 * *$ & $-0.165 * *$ & $-0.161 * *$ & & $-0.119 *$ \\
\hline HIV-III Role clarity & & & & & & $-0.153 * *$ \\
\hline $\begin{array}{l}\text { HIV-IV Role } \\
\text { conflicts }\end{array}$ & $-0.166^{* *}$ & $-0.183 * *$ & & & & \\
\hline
\end{tabular}


H1. High work demands positively correlate with mental health problems.

Based on the results of Pearson's $r$ correlations, it cannot be concluded whether work demands positively correlate with mental health problems. Some components of work demands have positive correlations with MHPs, but there are components that have negative correlations or do not correlate at all (see Table 3).

High workload, high work rates and uneven work patterns cause focus deficit, memory problems, and preclude clear thinking and decision making.

Cognitive demands when employees perceive that they have to deal with several things at the same time, and thus have to be innovative, will cause sleep disturbances and promote burnout.

High emotional demands in the workplace, emotionally disturbing situations, dealing with other people's personal problems, emotional coherence with their work, as well as sleep disturbances, burnout, stress, and somatic problems, such as head and abdominal pain, palpitations and muscle tension can occur.

H2. Positive relationships negatively correlate with mental health problems. This hypothesis cannot be rejected. Results of the analysis of correlations between "Interpersonal relationships and leadership" factor and MHPs show that there are usually negative correlations between positive relations and MHPs. The better are the relations within organization, the lower is the level of mental health problems among employees.

The lack of a sense of belonging and the lack of perception and cooperation encourage employees to experience depressive and cognitive symptoms. The lack of support from colleagues causes sleep disturbances, feeling of guilt, a decline in self-confidence, sadness and loss of interest to the issues happening in the surrounding. Leadership support is related to burnout, stress, depression, and cognitive symptoms.

The quality of management relates to all features of MHP and is influenced by such factors as planning work, staffing, employee valuation, and constructive resolution of configurations. Such factors as self-confidence of employees, feelings of sadness and guilt, and general interest in the surrounding (depersonalization) affect most of the working relationships. In addition, good working relationships and driving factors influence the cognitive abilities of the employees and, therefore, focus, clear thinking and readiness to make decisions.

H3. Individual negative work interfaces such as job insecurity and low job satisfaction positively correlate with mental health problems. It cannot be concluded whether there are any relations between individual negative work interfaces and MHPs. However, for specific components these connections are statistically significant (see "Adequate work organization"). Satisfaction with job is positively related to MHPs: employees with higher level of job satisfaction are less affected by MHPs than unsatisfied employees.

Work-life satisfaction is an essential component of employee mental health. Physical work environment, work prospects and ability to engage in work affect the employees' sense of security and safety and are an important component in terms of ensuring employee welfare. 
H4. Adequate work organization and job content negatively correlate with mental health problems. There are statistically significant negative correlations between work organization and job content and MHP. In organizations where the work processes are effectively managed and role conflicts are minimized, the level of MHPs is lower and the risk of mental health problems among employees is small.

Clear goals, responsibilities, expected results, work motivation and meanings are related to the appearance of cognitive symptoms among employees. Discordant tasks, unclear work instructions and demands, and unnecessary activities cause sleeping disturbances and burnout among employees.

\section{CONCLUSION}

Study results show that psychosocial risk factors influence mental health of care workers. We can see strong correlations between psychosocial risk factors and burnout, stress, sleep disorders, cognitive, depressive, and somatic symptoms. Emotional, social and psychological well-being are required to ensure the mental health of the workers. Workplaces should implement management practices that help create the working environment ensuring that the workers are more efficient and should maintain employee mental health at a good level. The following factors ensure a healthy working environment for the employees, colleagues, direct managers, and the management of the organization: good communication, teamwork, sufficient workforce, recognition, trust management, decision-making skills of co-workers and managers. Through these factors, supportive working environment and patient safety are ensured and work results are improved. Taking into account complexity of the health care environment, the threat to the patient safety, and quality of care, the collaboration with other healthcare professionals is vital.

Psychosocial risk factor such as work and family balance, rewards and the quality of leadership, commitment to the workplace showed positive correlation with all MHPs. Factors of rewards and quality of leadership and satisfaction with work have negative correlations with almost of MHPs.

Results of the study reveal that two out of four hypotheses ( $\mathrm{H} 2$ and $\mathrm{H} 4)$ were supported and the remaining two were partly supported ( $\mathrm{H} 1$ and $\mathrm{H} 3$ ). We can conclude that positive relationships at work decrease the risks of occurrence of mental health problems among the workers. Managers and employees should be educated on how to solve conflicts positively, how to support each other in routine working situations and how to give constructive feedback (H2). Our results showed that high cognitive demands at work correlate positively with sleep disorders and burnout problems, while quantitative demands at work correlate negatively (H1). Work organization and managers support are crucial in order to keep workers mental health stable (H4). It also helps increase workers' satisfaction (H3), motivation and commitment to provide quality care in nursing $(\mathrm{H} 4)$.

The healthcare management system should be preventive, flexible and oriented to continuous development and improvement. The prospects for healthcare authorities, principally nurses are to be offered operative and sustainable management to discourse the contests and costs of the system reorganisation. 
Economic panels that cause demands for the new models of care in nursing homes in order to reduce costs are important and contribute to the climate of improved management. Persistent concerns about nurses and management shortages sideways with criticisms of overloaded and displeased nursing personnel point to the significance of healthy and productive work environments in sustaining the health and well-being of nurses. Safety management challenges within different organisations were studied with a special focus on safety culture and climate, interrelationships between safety management systems and organizational factors.

Therefore, the role of management style and competence should be emphasized and studied as effective intervention and management of psychosocial risk factors.

\section{REFERENCES}

Aiken, L.H., \& Patrician, P.A. (2000). Measuring Organizational Traits of Hospitals: the Revised Nursing Work Index. Nursing Research, 49(3), 146-153. https://doi.org/10.1097/00006199-200005000-00006

Begat, I., Ellefsen, B., \& Severinsson, E. (2005). Nurses' Satisfaction with their Work Environment and the Outcomes of Clinical Nursing Supervision on Nurses' Experiences of Well-Being - Norwegian Study. Journal of Nursing Management, 13(3), 221-230. https://doi.org/10.1111/j.1365-2834.2004.00527.x

Duncan, S., Rodney, P.A., \& Thorne, S. (2014). Forging a Strong Nursing Future: Insights from the Canadian Context. Journal of Research in Nursing, 19(7-8), 621-633. https://doi.org/10.1177/1744987114559063

Edberg, A., Bird, M., Richards, D.A. Woods, R., Keeley, P., \& Davis-Quarrell, V. (2008). Strain in Nursing Care of people with Dementia: Nurses' Experience in Australia, Sweden and United Kingdom. Aging \& Mental Health, 12(2), 236-243. https://doi.org/10.1080/13607860701616374

Hamdan, M. (2013). Measuring Safety Culture in Palestinian Neonatal Intensive Care Unit Using the Safety Attitudes Questionnaire. Journal of Critical Care, 28(5), 886e7-886e14. https://doi.org/10.1016/j.jcrc.2013.06.002

Freimann, T., Coggon, D., Merisalu, E., Animägi, L. \& Pääsuke, M. (2013). Risk Factors for Musculoskeletal Pain Amongst Nurses in Estonia: A Cross-Sectional Study. BMC Musculoskeletal Disorders, 14, 334. https://doi.org/10.1186/1471-2474-14-334

Freimann, T. \& Merisalu, E. (2015). Work-Related Psychosocial Risk Factors and Mental Health Problems Amongst Nurses at a University Hospital in Estonia: A Cross-Sectional Study. Scandinavian Journal of Work Environment Health, 43(5), 447-452. https://doi.org/10.1177/1403494815579477

Freimann, T., Pääsuke, M. \& Merisalu, E. (2016). Work-Related Psychosocial Factors and Mental Health Problems Associated with Musculoskeletal Pain in Nurses: A Cross-Sectional Study. Pain Research and Management, ID 9361016, 7 pp. http://dx.doi.org/10.1155/2016/9361016

Gabriel, P., \& Liimatainen, M.-R. (2000). Mental Health in the Workplace. Introduction Executive Summaries. Geneva: International Labour Organization. Retrieved from https://digitalcommons.ilr.cornell.edu/cgi/viewcontent.cgi?article=1224\&context=gladnetcollect

German, P.B., \& Gumming, G. (2010). The Influence of Nursing Leadership on Nurse Performance: A Systematic Literature Review. Journal of Nursing Management, 18(4), 425-439. https://doi.org/10.1111/j.1365-2834.2010.01100.x

Giurgiu, D.I., Geoffrion, C., Grasset, B., Dessomme, B.K., Moret, L., Roquelaure, Y., Caubet, A., Verger, C., Laraqui, C.E.H., Lombrail, P., Geraut, C., \& Tripodi, D. (2015). Psychosocial and Occupational Risk Perception among Health Care Workers: a Moroccan Multicenter Study, BMC Res Notes, 8(408), 1- 10. https://doi.org/ 10.1186/s13104-015-1326-2

Javaid, M.U., Isha, A.S.N., Ghazali, Z., \& Nübling, M. (2018). Does Psychosocial Work Environment Factors Predict Stress and Mean Arterial Pressure in the Malaysia Industry Workers? BioMed Research International, ID 9563714, 1 - 11. https://doi.org/10.1155/2018/9563714

Järvis, M., \& Tint, P. (2009). The Formation of a Good Safety Culture at Enterprise. Journal of Business Economics and Management, 10(2), 169-180. https://doi.org/10.3846/1611-1699.2009.10.169-180

Kleimann, L., Frank, L., Ciesla, G., Rupnow, M., \& Brodaty, H. (2004). Psychometric Performance of an Assessment Scale for Strain in Nursing Care: the M-NCAS. Health Quality of Life Outcomes, 2(62), 1-10. https://doi.org/10.1186/1477-7525-2-62

Kristensen, T.S., Hannerz, H., Hųgh, A., Born, V. (2005). The Copenhagen Psychosocial Questionnaire (COPSOQ) - A tool for the Assessment and Improvement of the Psychosocial Work Environment. Scandinavian Journal of Work Environment Health, 31(6), 438-449. https://doi.org/10.5271/sjweh.948 
Lambert, V.A., \& Lambert, C.E. (2001). Literature Review of Role Stress/Strain on Nurses: an International Perspective. Nursing \& Health Sciences Journal, 3(3), 161-172. https://doi.org/10.1046/j.14422018.2001.00086.x

Leka, S., \& Jain, A. (2010). Health Impact of Psychosocial Hazards at Work: An Overview. Geneva: World Health Organization. Retrieved from http://www.who.int/iris/handle/10665/44428

Leka, S., Van Wassenhove, W., \& Jain, A. (2015). Is Psychosocial Risk Prevention Possible? Deconstructing Common Presumptions. Safety Science, 71(A), 61-67. http://dx.doi.org/10.1016/j.ssci.2014.03.014

Lewis, R., Yarker, J., Donaldson-Feilder, E., Flaxman, P., Munir, F. (2010). Using a Competency-Based Approach to Identify the Management Behaviours Required to Manage Workplace Stress in Nursing: a Critical Incident Study. International Journal of Nurses Studies, 47(3), 307-313. https://doi.org/10.1016/j.ijnurstu.2009.07.004

Lim, J., Bogossian, F., \& Ahem, K. (2010). Stress and Coping in Australian Nurses: a Systematic Review. International Nursing Review, 57(1), 22-31. https://doi.org/10.1111/j.1466-7657.2009.00765.x

Malloy, T., \& Penprase, B. (2010). Nursing Leadership Style and Psychosocial Work Environment. Journal of Nursing Management, 18(6), 715-725. https://doi.org/10.1111/j.1365-2834.2010.01094.x

McHugh, M.D., Kutney-Lee, A., Cimiotti, J.P., Sloane, D.M., Aiken, L.M. (2011). Nurses' Widespread Job Dissatisfaction, Burnout, and Frustration with Health Benefits Signal Problems for Patient Care. Health Affairs (Millwood), 30(2), 202-210. https://doi.org/10.1377/hlthaff.2010.0100

Olsen, K. (2012). Occupational Health and Safety Professionals Strategies to Improve Working Environment and their Self-Assessed Impact, Work - A Journal of Prevention Assessment \& Rehabilitation, 2012, 41, 2625-2632. https://doi.org/10.3233/WOR-2012-0506-2625

Ribbe, M.W., Ljunggren, G., Steel, K., Topinkova, E., Hawes, C., Ikegami, N., Henrard, J.-C., Jonnson, P.V. (1997). Nursing Homes in 10 Nations: A Comparison Between Countries and Settings. Age and Ageing, 26(2), 3-12. https://doi.org/10.1093/ageing/26.suppl_2.3

Sepp, J., Järvis, M., Tint, P., Siirak, V., Reinhold, K. (2015). EMG Measurement of Thumb Muscles of Nurses and Caregivers. Agronomy Research, 13(3), 836-845. Retrieved from https://www.etis.ee/Portal/Publications/Display/d2fee671-e824-4a27-816f-33e3cc8e18d9

Sepp, J., \& Tint, P. (2017). The Components of Non-Punitive Environment in Nursing. Safety of Technogenic Environment, 8(1), 24-30. https://doi.org/10.1515/ste-2017-0004

Steel, K., Sherwood, S., \& Ribbe, M.W. (1997). The Future: A Person-Specific Standardized Assessment Instrument. Age Ageing, 26(S2), 83-85. Retrieved from https://goo.gl/8PmcAa

Titzer, J.I., Shirey, M.R., \& Hauck, S. (2014). A Nurse Manager Succession Planning Model with Associated Empirical Outcomes. Journal of Nursing Administration, 44(1), 37-46. https://doi.org/10.1097/NNA.0000000000000019

Toode, K., Routasalo, P., Helminen, M., \& Suominen, T. (2015). Hospital Nurses' Working Conditions in Relation to Motivation and Patient Safety. Nursing Management, 21(10), 31-41. https://doi.org/10.7748/nm.21.10.31.e1293

Van Beek, I., Hu, Q., Schaufeli, W., Taris, T.W., Schreurs, B. H. J. (2012). For Fun, Love, or Money: What Drives Workaholic, Engaged, and Burned-Out Employees at Work? Applied Psychology: An International Review, 61(1), 30-55. https://doi.org/10.1111/j.1464-0597.2011.00454.x

Van den- Pol-Grevelink, A., Jukema, J.S., \& Smits, C.H.M. (2011). Person-Centred Care and Job Satisfaction of Caregivers in Nursing Homes: A Systematic Review of the Impact of Different Forms of Person-Centred Care on Various Dimensions of Job Satisfaction. International Journal of Geriatric Psychiatry, 27(3), 219229. https://doi.org/10.1002/gps.2719

Zaree T. Y., Nazari J., Jafarabadi M. A., Alinia T. (2017). Impact of Psychosocial Factors on Occurrence of Medication Errors among Tehran Public Hospitals Nurses by Evaluating the Balance between Effort and Reward. Safety and Health at Work, 9(4), 447-453. https://doi.org/10.1016/j.shaw.2017.12.005

Zimmermann, S., Williams, C.S., Reed, P.S., Boustani, M., Preisser, J.S., Heck, E., Sloane, P.D. (2005). Attitudes, Stress and Satisfaction of Staff Who Care for Residents with Dementia. Gerontologist, 45((1), 96-105. https://doi.org/10.1093/geront/45.suppl_1.96 


\section{AUTHORS' SHORT BIOGRAPHIES}
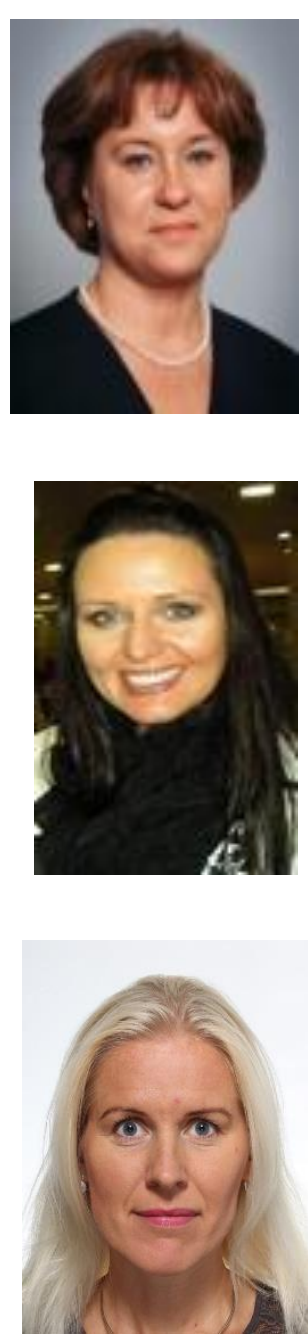

Jaana Sepp is the head of the educational department in Tallinn Health Care College. She has two Master of Science degrees, one from Tallinn University as a psychologist (The Connection between the Motives for Joining the Defence Forces, Perceived Organizational Support and the Reasons for leaving, 2008) and one from Tartu University as a sociologist (Evaluation of the Need for Psychometric Tests in the Inclusive Education by Teachers and School Psychologist, 2013).

Nowadays she is a PhD student of Tallinn University of Technology, Department of Business Administration and her topic is "Proactive safety management in healthcaretowards a broader view of wellbeing among healthcare employees".

She has 10 scientific publications and her $\mathrm{PhD}$ thesis is in the final stage.

E-Mail: jaana.sepp@ttk.ee

ORCID ID: https://orcid.org/0000-0003-1624-8580

Marina Järvis is an assoc. professor of safety management in Tallinn University of Technology (TTU), School of Business and Governance. She defended her $\mathrm{PhD}$ in 2013 in TTU in business administration. She holds an MSc degree in occupational health from Bergen University, Norway. She has published 40 scientific papers; she has represented Estonia at the international OH\&S conferences many times and participated in relevant projects. Her research interests focus on safety culture, knowledge management in OH\&S; safety management system; occupational wellbeing.

E-mail: Marina.Jarvis@ taltech.ee

ORCID ID: https://orcid.org/0000-0002-4541-4632

Karin Reinhold is an assoc. professor of occupational health and safety management in Tallinn University of Technology (TTU), School of Business and Governance. She defended her PhD in Material Science in TTU in 2008. She has taken part in many advanced courses in occupational health of NIVA (Nordic Council of Ministers). She has published 50 scientific papers; she has represented Estonia at the international OH\&S conferences many times and participated in relevant projects. Her research interests focus on safety management, chemical safety, risk analysis in the work environment, measurements in the work environment, and occupational wellbeing.

E-mail: karin.reinhold@ taltech.ee

ORCID ID: https://orcid.org/0000-0003-3608-2354 